\title{
Industrial robots application in the construction of buildings and structures
}

\author{
Gennady Verzhbovskiy, ${ }^{1, *}$ and Alexey Reshetnikov ${ }^{1}$ \\ ${ }^{1}$ Don State Technical University, Gagarin square 1, Rostov-on-Don, 344000, Russia
}

\begin{abstract}
Proposals on the use of modernized industrial robots in the construction of low-rise buildings are formulated. The necessary parameters of such a mechanism are established. The time necessary for building the walls of a two-story house is determined. Features of the robots use on the construction site are described.
\end{abstract}

\section{Introduction}

As a rule, sets of products for the erection of buildings and structures, produced within one enterprise, are characterized by constant dimensions and high quality, that turns the construction process into a rigorous set of simple operations for the sequenced lifting, transfer and installation in a specific place and in a certain order of the structure details. In industry, similar actions have long been performed by robotic manipulators. When they are used in production, there are a number of positive points:

- in the process of performing monotonous operations, the "human factor" does not appear;

- they can work in environment dangerous for human life and health;

- they can work around the clock, without days off and holidays;

- the accuracy of part positioning in the assembly is much higher than that of a person;

- the percentage of defects is minimized.

Robots in construction are no longer fiction. Back in 1984, the USSR issued the state standard "Manipulators for construction and installation works. General technical requirements" [1]. However, in Russia they are used in construction very rarely. First, the robotization of building is constrained by the fact that each project is unique and requires the use of various high-tech solutions. Secondly, the use of robots, for example, in the creation of concrete frameworks, is associated with the need to use expensive construction mixtures with hardening high speed, formless and nonarmature construction technologies, otherwise the efficiency of using complex equipment will be lost. Third, the cost of robots is still high.

Experts believe that in future robots will be actively used in low-rise construction [2]. Their application allows to reduce time and money costs by several times, and also provides high accuracy of construction. Several years ago, an attempt to create a construction robot designed for the mechanization of masonry was undertaken by scientists from the Robotics and Microelectronics Laboratory of the Russian Academy of Sciences. The main reason for the unpopularity of such technologies in Russia is that the cost of housing does not depend on the cost of labor, so, it is more profitable to use labor of migrants, who receive less wages than professional workers.

Abroad, the process of robotics is very intense. Thus, Fabio Gramasio and Matthias Kohler, professors at the Institute of Architectural Technology ETH Zurich in Switzerland, were among the first to use robots in the field of architecture and design [3]. Since 2006, they have investigated various production technologies and the application of a wide range of different materials to create buildings by robots. Their studio Gramazio \& Kohler produces complex designs, which are then used to build unusual structures in Zurich, London, Barcelona, New York, and other places (Figure 1).

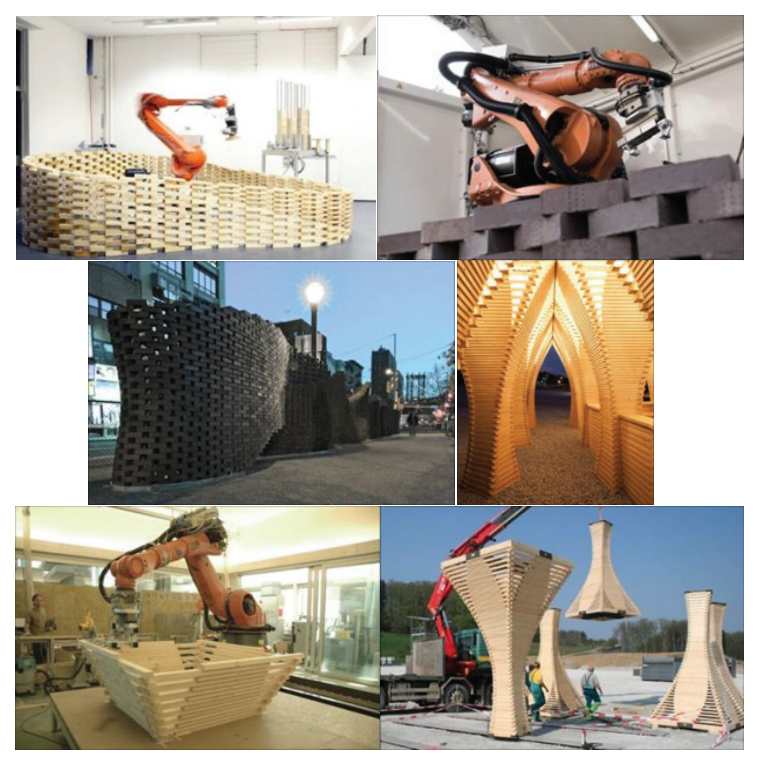

Fig. 1. The works of the studio Gramazio \& Kohler

\footnotetext{
* Corresponding author: vergen2005@yandex.ru
} 
The peculiarity of these structures is that they are assembled from separate elements, installed in the design position with a high degree of accuracy by a special algorithm.

Scientists in Japan, the United Kingdom and the United States are simultaneously developing 3D building printers that "print" buildings from monolithic reinforced concrete. There is information about similar studies in Spain - the project "Stone Spray". All this proves that the use of robots in construction is a promising direction in the development of the industry.

\section{Problem formulation}

Accuracy and constancy of the factory-made products sizes and their predetermined location in the building structure make it possible to automate the process of erecting the building. To solve the task, it is necessary to determine first the required parameters of the robot manipulator.

Industrial robots (IR) are characterized by a set of basic data such as load capacity, number of degrees of freedom, work area, mobility, positioning accuracy and speed of movement [4]. Load-carrying capacity is the greatest total effort developed by the operating bodies of the IR. If the weight of the element exceeds $160 \mathrm{~kg}$, the robots are considered as heavy ones.

The number of degrees of freedom is the sum of all manipulator brush possible movements without taking into account the gripping and clamping. In general, six degrees of freedom are necessary to move and orient bodies in space, although two or three degrees are sufficient for certain operations. As it turns out from the following discussion, when erecting buildings, it is irrational to limit the movement of the manipulator.

The working area is defined by the space in which the gripper can operate. It is characterized either by the volume serviced by the manipulator or by the magnitude of the greatest displacement along each coordinate and around. Since we are considering low-rise buildings, we agree to limit the working area to $25 \times 20$ meters in plan and 15 meters in height.

Mobility is the ability of a robot to perform local, regional and global movements. Local ones called the movements of the manipulator, necessary for the final installation of the product in the design position. They are rotations and minor linear movements of the working member. Regional ones are movements of the grip in different areas of the working space, determined by the size of the arm links, and also commensurate with the size of the equipment to be serviced. Global one is a movement of the manipulator at distances exceeding both the dimensions of the industrial robot itself and the equipment size. Due to the fact that building materials are usually stored near the object under construction, the IR must be able to perform all of these types of movements. In the literature such mechanisms are called nonstationary.

Positioning accuracy is the greatest deviation of the gripping device from a given position at a certain fixed point with multiply repetition of the cycle. The most common industrial robots with positioning accuracy of about $0,2-0,3 \mathrm{~mm}$ are applied, and such accuracy is quite sufficient for construction.

Most modern manipulators have a linear arm speed up to $1,5 \mathrm{~m} / \mathrm{s}$, and angular velocity up to $180 \mathrm{grad} / \mathrm{s}$. Taking in account the construction of the facility is conducted in the open air and in various weather conditions, it is irrational to use the maximum values, so it is suggested to limit the speed to $1 \mathrm{~m} / \mathrm{s}$ and $90 \mathrm{grad} / \mathrm{sec}$. In this case, the robot will be able to transfer a separate element along the entire working area in just 25 seconds, so it is a good indicator.

\section{Results and its discussion}

As a result, we can conclude that for the construction of low-rise buildings and structures, a heavy non-stationary robot with six degrees of freedom of the manipulator, positioning accuracy of $0,2-0,3 \mathrm{~mm}$, average speeds and adjustable working area with maximum dimensions of $25 \times 20 \times 15 \mathrm{~m}(\mathrm{LxWxH})$ is needed. To facilitate the installation of extended elements, such as joists, it is convenient to use a technique with two grippers, so another condition is the presence of two independent working bodies. Finally, the various operations carried out on the construction site require the use of replaceable attachments.

A serious proof of the expediency use robots can be the determination of the time spent on the wall blocks installation. It is assumed that the building is erected in a "dry" way and interlocking and interchamber fixators are used to fix the blocks [5].

Suppose that we need to install 3 blocks at the same time at a height of 6 meters to the wall located in the 15 meters from the place of their storage. Let's consider that the height of a stack is 1 meter, and the robot, whose actuator is above the installation site at an altitude of 6,5 meters, can perform motions and rotations only sequentially. It is more convenient to calculate the required time in a tabular form.

Table 1. Calculation of the time required for the robot to install three wall blocks (beginning)

\begin{tabular}{|c|l|c|}
\hline \multicolumn{1}{|c|}{ Contents of the operation } & $\begin{array}{c}\text { Duration } \\
\text { of the } \\
\text { operation, } \\
\text { s }\end{array}$ \\
\hline 1 & $\begin{array}{l}\text { Moving the manipulator to the storage } \\
\text { location }\end{array}$ & 15 \\
\hline 2 & $\begin{array}{l}\text { Positioning of the gripper above the } \\
\text { blocks }\end{array}$ & 5 \\
\hline 3 & $\begin{array}{l}\text { Descent from a height of } 6,5 \text { meters and } \\
\text { blocks capture }\end{array}$ & 10 \\
\hline 4 & $\begin{array}{l}\text { Lifting of the gripper at 1 meter, its } \\
\text { rotation and placement above the } \\
\text { interlace clamps }\end{array}$ & 8 \\
\hline 5 & Release and lock of latches & 3 \\
\hline 6 & $\begin{array}{l}\text { Lifting of the gripper at 1 meter, its } \\
\text { rotation and placement above the } \\
\text { interlock clamps }\end{array}$ & 8 \\
\hline 7 & Release and lock of latches & 3 \\
\hline
\end{tabular}


Table 1. Calculation of the time required for the robot to install three wall blocks (end of table)

\begin{tabular}{|c|c|c|}
\hline 8 & $\begin{array}{l}\text { Lifting the manipulator to a height of } \\
6,5 \text { meters }\end{array}$ & 8 \\
\hline 9 & $\begin{array}{l}\text { Rotate the gripper to the position } \\
\text { required to install the blocks }\end{array}$ & 3 \\
\hline 10 & $\begin{array}{l}\text { Moving the manipulator to the } \\
\text { installation site }\end{array}$ & 15 \\
\hline 11 & Positioning the gripper & 5 \\
\hline 12 & 0,5 meter descent and units installation & 3 \\
\hline 13 & $\begin{array}{l}\text { Lifting the manipulator at } 1 \text { meter and } \\
\text { turning it to } 90^{\circ} \text { to insert the interlace } \\
\text { clamps }\end{array}$ & 3 \\
\hline 14 & 1 meter descent and fixing installation & 3 \\
\hline 15 & $\begin{array}{l}\text { Lifting of the manipulator by one meter } \\
\text { and its rotation to } 90^{\circ} \text { for insertion of } \\
\text { interlock clamps }\end{array}$ & 3 \\
\hline 16 & 1 meter descent and fixing installation & 3 \\
\hline 17 & $\begin{array}{l}\text { Lifting the gripper to } 0,5 \text { meters and } \\
\text { turning it to } 180^{\circ} \text { for subsequent } \\
\text { operations }\end{array}$ & 3 \\
\hline & Total & 101 \\
\hline
\end{tabular}

When determining the time required for performing the operations in Table 6.4, one second was added to each change the way the manipulator moves. Taking in account possible unforeseen circumstances, let's increase the time required for installing the units up to two minutes. With the parallel operation of the two grippers, it takes about twenty seconds to fix one element to the wall. During 23 hours the robot will be able to install 4100 wall blocks. Approximate calculations show that the walls of a two-storey building in this way can be erected in one day instead of six, required by a team of builders. The indicated term can be even less if in the robot base design there is a site for installing a stack with mounted elements.

Let us turn to the consideration of applied questions connected with the use of such equipment on the construction site. First of all, it is a possible robot design. It is proposed to be performed as a reach truck. Reach truck is a type of a high-lift stacker with a counterweight and a retractable mast that is one of the high-tech types of warehouse equipment (figure 2).

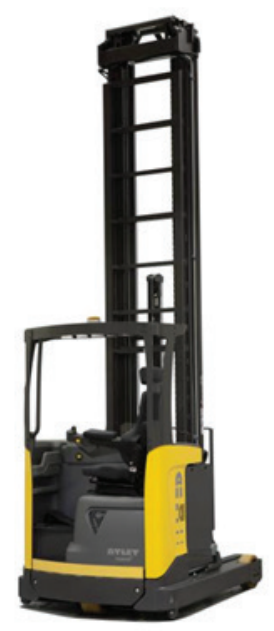

Fig. 2. Reach track with counterweight and telescopic lift
The robot on the specified mechanism basis should move along the building under construction on special guides, and instead of the forks intended for carrying cargoes, it should have the manipulator installed on it. Two similar mechanisms are installed on both sides of the object and controlled by one computer with a specialized program. The approximate location of the robot on the construction site is shown in Figure 3.

The robotic construction process has its own characteristics and is somewhat different from the standard human one. So, for example, when moving an object into nature, there is no need to secure all the centering axes. It is quite simple to define three any characteristic points of a building that do not lie on one straight line. It is the most convenient to indicate the position of the corners of the structure.

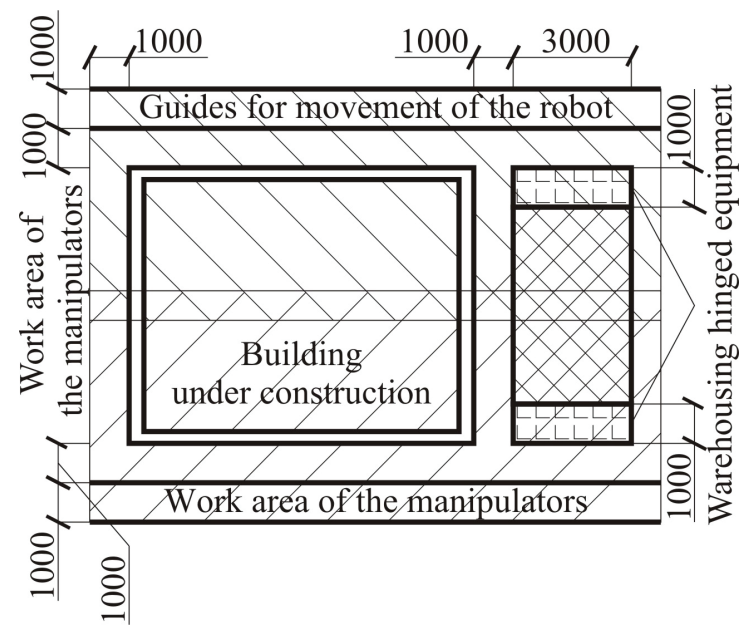

Fig. 3. Possible robots location on the construction site

After removal of the object, installation of guides for the robot movement is carried out. In principle, these can be flat slabs laid on a planned base. For example, they can be the composite road surfaces "MDP-MOBISTEK" shown in Figure 4 [6].

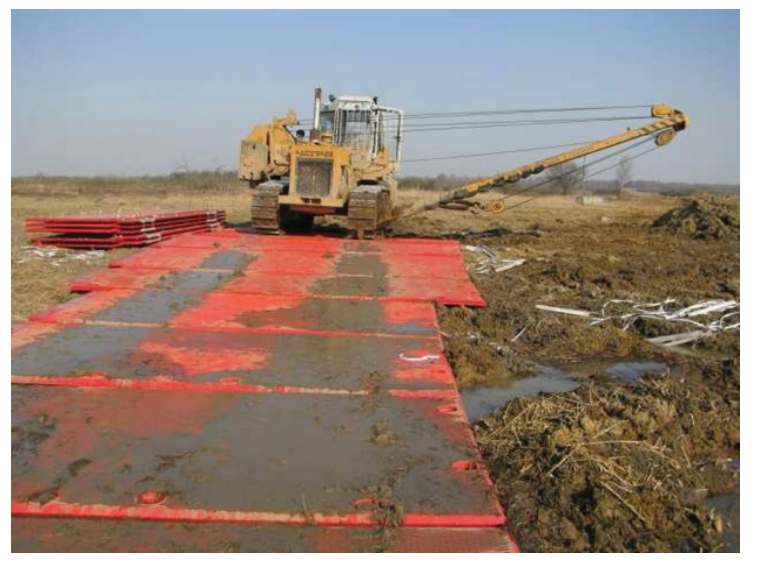

Fig. 4. Prefabricated composite road surface "MDP-Mobystek"

The result of this operation should be a surface without kinks at the joints. Global misalignments of guides, associated with the relief of the site, are completely acceptable. Prior to construction, the mounted on the rails robots produce a high-altitude 
survey of the base profile and form the necessary corrections to the assembled parts coordinates.

The next stage is the organization of storage areas for materials and attachments. Builders determine the location of inventory pallets with removable devices for manipulators relative to the guides and prepare a place from which the building elements will be taken automatically. The supply of materials to this zone is made by workers. The most convenient is the stacks with products installation on special carts, which are placed on the site in the spaces appropriate for them. They can be allocated with special restrictors fixed in the storage area. Precise positioning simplifies the robots work and minimizes the possible errors. The pallets stacking to the carts must be carried out outside the working area of the robots. The order of parts placement in the storage is determined by the assembly instruction.

\section{Conclusions}

It is theoretically possible to automate the whole process of building, but it is hardly advisable at the current level of technology development. So, for example, a robot can easily cope with drilling wells or digging trenches for foundations, but backfilling is more convenient by workers. Separate actions on the device of engineering networks in a building are easier for man to carry out. We can specify some other operations, where the use of robots is economically unprofitable. Thus, we are talking about the joint work of robots and man, as it is organized in a number of industrial productions.

Round-the-clock robotic construction assumes threeshift work of the personnel, therefore the standard brigade of builders is unlikely to be reduced, but a significant reduction in the construction time will reduce the cost of providing workers and the costs associated with the operation of construction equipment.

The proposed innovative technology makes it possible to organize an analogue of industrial production on the construction site, which will allow creating objects with high quality and in a short time.

\section{References}

1. Manipulators for building. General technical requirements, GOST 26055-84 (Moscow, Publishing house of standards, 1984)

2. V.V. Nemchenko, Building robots - a new class of cars, Workshop. Modern construction 3, 25 (2013)

3. Architects using robots to create amazing and beautiful structures, Tzoom-news portal. Informational-educational project, Available: http://www.tzoom.com.ua/arxitektory-ispolzuyarobotov-sozdayut-udivitelnye-i-krasivye-stroeniya/. Last accessed 2.12.2013 (2013)

4. A.G. Bulgakov and others, Automation and robotization of building processes and productions (Moscow, Russian Engineering Academy, 2006)

5. G.B. Verzhbovskiy, Low-rise prefabricated buildings and structures made of composite materials (Rostov-on-Don, LLC Publisher Bara, 2015)

6. Mobile road surface MDP-Mobystek, Available: http://gazpromss.ru/production

/road_reinforcing/84/. Last accessed 13.10.2013 (2013) 